06

\title{
Влияние технологии получения ферритизированного порошка на степень магнитной текстуры пластин гексаферритов $\mathrm{BaFe}_{12} \mathrm{O}_{19}$ и $\mathrm{SrFe}_{12} \mathrm{O}_{19}$
}

\section{(C) А.В. Тимофееев, В.Г. Костишин, Д.Н. Читанов}

Национальный исследовательский технологический университет „МИСиС“, Москва, Россия

E-mail: andtim2011@gmail.com

Поступило в Редакцию 17 января 2019 г.

В окончательной редакции 17 января 2019 г.

Принято к публикации 23 января 2019 г.

Изучено влияние технологии получения ферритизированного порошка гексаферритов бария и стронция на степень магнитной текстуры пластин на их основе. Показано, что по сравнению с керамической технологией использование технологии химического соосаждения позволяет получать в пластинах гексаферритов при тех же значениях магнитного поля прессования сырых заготовок степень магнитной текстуры на $19-22 \%$ выше.

DOI: 10.21883/PJTF.2019.08.47619.17706

Ферриты на базе систем $\mathrm{BaO}-\mathrm{Fe}_{2} \mathrm{O}_{3}$ и $\mathrm{SrO}-\mathrm{Fe}_{2} \mathrm{O}_{3}$ относятся к классу магнитотвердых материалов и широко применяются в качестве постоянных магнитов [1]. Как известно, частицы гексаферритов типа $M$ имеют несферическую форму и кристаллы растут преимущественно в базисной плоскости (медленнее всего вдоль оси) [2].

На основе пластин гексаферритов могут быть получены анизотропные магниты с высокими значениями магнитной энергии, а также подложки с высокой степенью магнитной текстуры для современных высокодобротных микрополосковых устройств сверхвысокочастотной электроники, работающих в миллиметровой области длин волн [3]. Достигается это прессованием сырых заготовок в присутствии магнитного поля, приложенного вдоль направления оси прессования.

Степень магнитной текстуры заготовки гексаферрита определяется формой частиц порошка гексаферрита и однородностью их распределения по размерам, с одной стороны, и величиной приложенного магнитного поля, с другой стороны.

Метод химического соосаждения позволяет получать частицы гексаферрита с большей однородностью распределения по размерам, а также существенно меньших размеров, чем метод традиционной керамической технологии [4-7]. Поскольку меньшие по размеру частицы гексаферрита легче сориентировать в магнитном поле, это позволит получить высокие значения степени магнитной текстуры в пластинах гексаферритов при меньших энергетических затратах.

Цель настоящей работы состоит в изучении влияния технологии получения ферритизированного порошка гексаферрита на степень магнитной текстуры пластин.

Образцы порошков гексаферритов $\mathrm{BaFe}_{12} \mathrm{O}_{19}$ и $\mathrm{SrFe}_{12} \mathrm{O}_{19}$, полученные с помощью классической керамической технологии и метода химического соосаждения, подробно описанного в работах $[8,9]$, исследовались на сканирующих электронных микроскопах JEOL JSM7800F и MIRA3 TESCAN.

Из имеющихся порошков гексаферритов были спрессованы сырые заготовки: $\mathrm{BaFe}_{12} \mathrm{O}_{19}$ (керамическая технология), $\mathrm{SrFe}_{12} \mathrm{O}_{19}$ (керамическая технология), $\mathrm{BaFe}_{12} \mathrm{O}_{19}$ (технология химического соосаждения) и $\mathrm{SrFe}_{12} \mathrm{O}_{19}$ (технология химического соосаждения). Сырые заготовки имели форму шайб диаметром $10 \mathrm{~mm}$ и толщиной $3.0 \mathrm{~mm}$. Используемое давление прессования равнялось $8 \mathrm{MPa}$, величина намагничивающего поля в конце прессования составляла $6.5 \mathrm{kOe}$. После прессования сырые заготовки сушились в естественных условиях в течение двух суток, после чего проводилась операция спекания в печи с резистивным нагревом при температуре $1200^{\circ} \mathrm{C}$ в течение $2 \mathrm{~h}$.

Степень магнитной текстуры образцов оценивалась по формуле

$$
D=\left[1-\frac{B_{r \perp}}{B_{r \|}}\right] \cdot 100,
$$

где $D$ - степень магнитной текстуры (в процентах); $B_{r \perp}$ и $B_{r \|}-$ остаточная магнитная индукция поперек и вдоль оси текстуры соответственно.

На рис. 1-3 представлены при различных увеличениях фотографии ферритизированных порошков: $\mathrm{BaFe}_{12} \mathrm{O}_{19}$, керамическая технология (рис. 1); $\mathrm{BaFe}_{12} \mathrm{O}_{19}$, технология химического соосаждения (рис. 2); $\mathrm{SrFe}_{12} \mathrm{O}_{19}$, технология химического соосаждения (рис. 3).

Как видно из представленных микрофотографий, для порошка гексаферрита, полученного по традиционной керамической технологии (изображение порошка гексаферрита стронция, полученного по керамической технологии, было сходно с изображением гексаферрита бария, представленным на рис. 1), характерны неправильная форма частиц и большой разброс по размерам. В то же время для порошков гексаферритов, полученных методом химического соосаждения, наблюдается правильная 
Значения степени магнитной текстуры пластин гексаферритов бария и стронция в зависимости от технологии получения ферритового порошка

\begin{tabular}{c|c|c|c}
\hline № п/п & Химический состав порошка & Технология получения порошка & Степень магнитной текстуры, \% \\
\hline 1 & $\mathrm{BaFe}_{12} \mathrm{O}_{19}$ & Традиционная керамическая технология & 69 \\
2 & $\mathrm{SrFe}_{12} \mathrm{O}_{19}$ & То же & 70 \\
3 & $\mathrm{BaFe}_{12} \mathrm{O}_{19}$ & Технология химического соосаждения & 91 \\
4 & $\mathrm{SrFe}_{12} \mathrm{O}_{19}$ & То же & 89
\end{tabular}
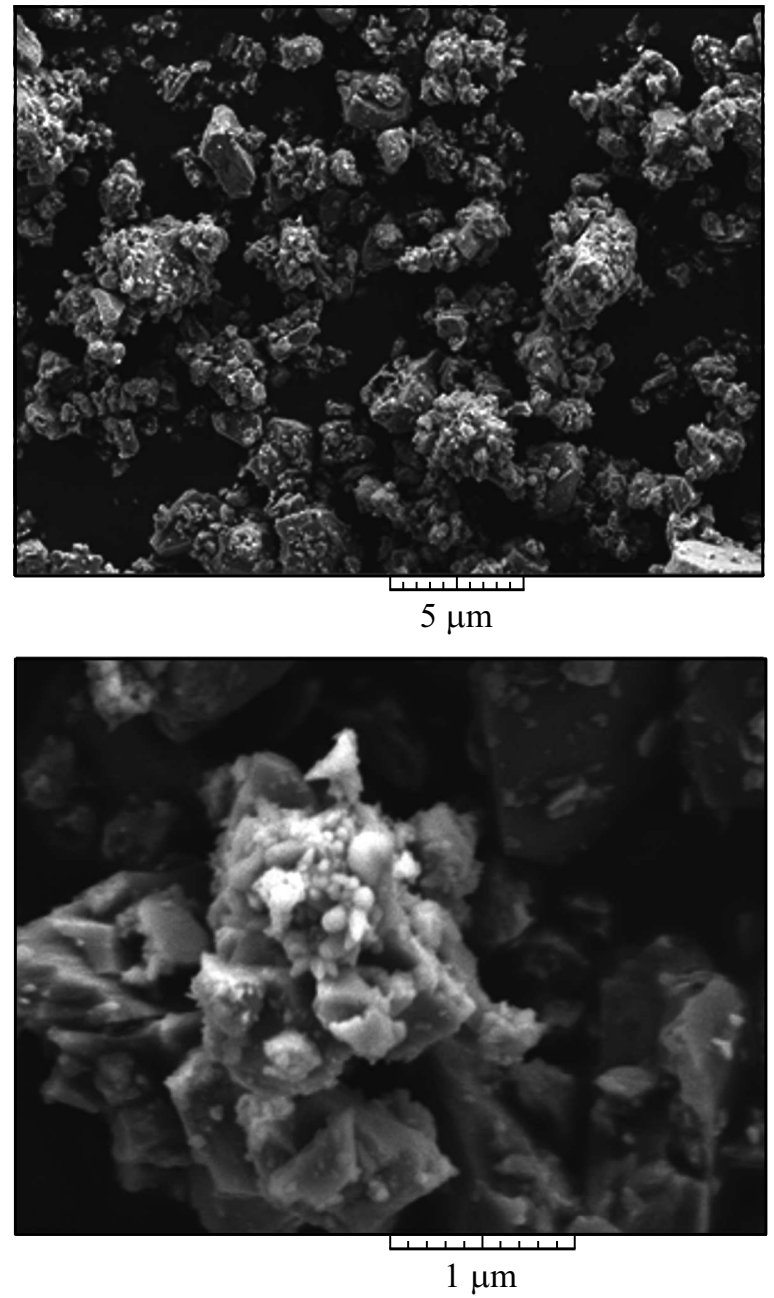

Рис. 1. Микрофотографии порошка гексаферрита бария, полученного методом традиционной керамической технологии, при различных увеличениях.

пластинчатая форма частиц и небольшой их разброс по размерам.

В таблице представлены определенные значения степени магнитной текстуры изученных порошков.

Как видно из данных таблицы, технология химического соосаждения является весьма эффективной по сравнению с традиционной керамической технологией для получения пластин гексаферритов с высокой степенью магнитной текстуры. В пластинах на основе порошков гексаферритов, полученных методом химического соосаждения, удается достичь степени магнитной текстуры $\sim 90 \%$, т.е. на 19-22\% выше, чем при тех же условиях и на том же оборудовании позволяет достичь традиционная керамическая технология.

Таким образом, изучено влияние технологии получения ферритизированного порошка на степень магнитной текстуры пластин на основе гексаферритов $\mathrm{BaFe}_{12} \mathrm{O}_{19}$ и $\mathrm{SrFe}_{12} \mathrm{O}_{19}$. Как показали исследования, порошки гексаферритов, полученные по технологии химического
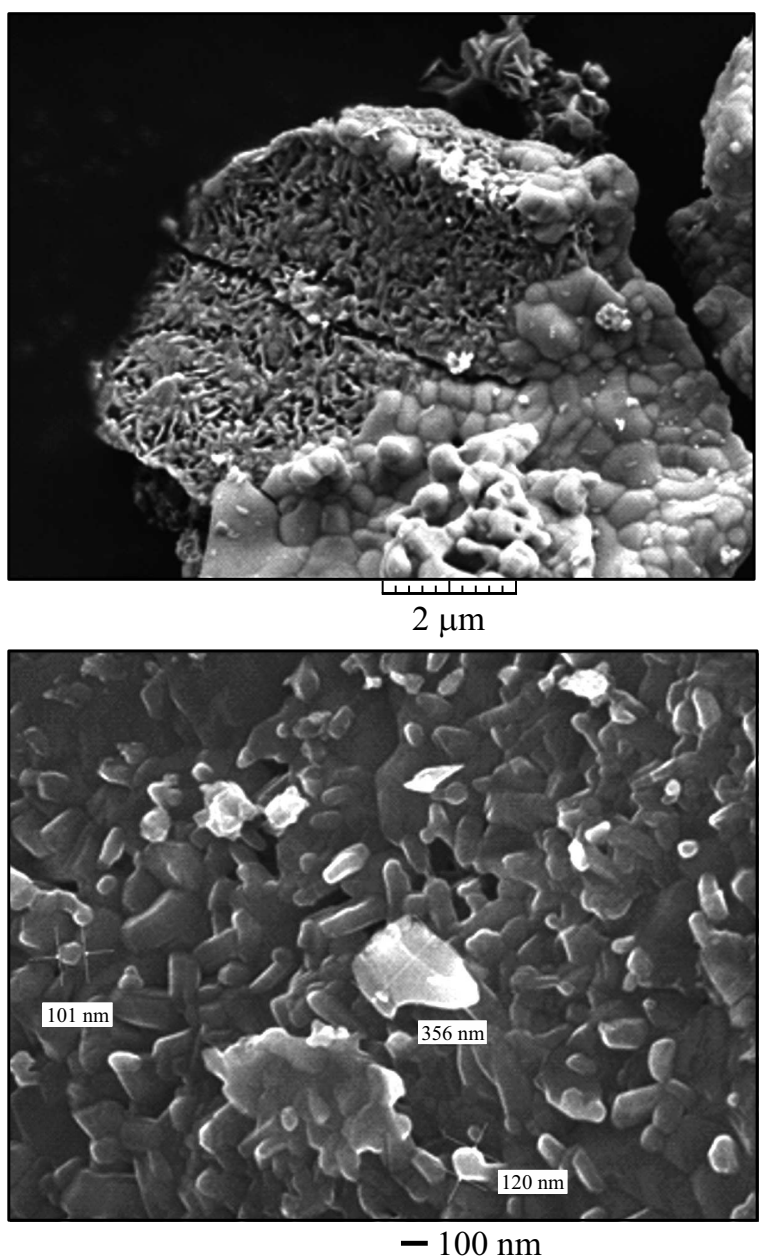

Рис. 2. Микрофотографии порошка гексаферрита бария, полученного методом химического соосаждения, при различных увеличениях. 

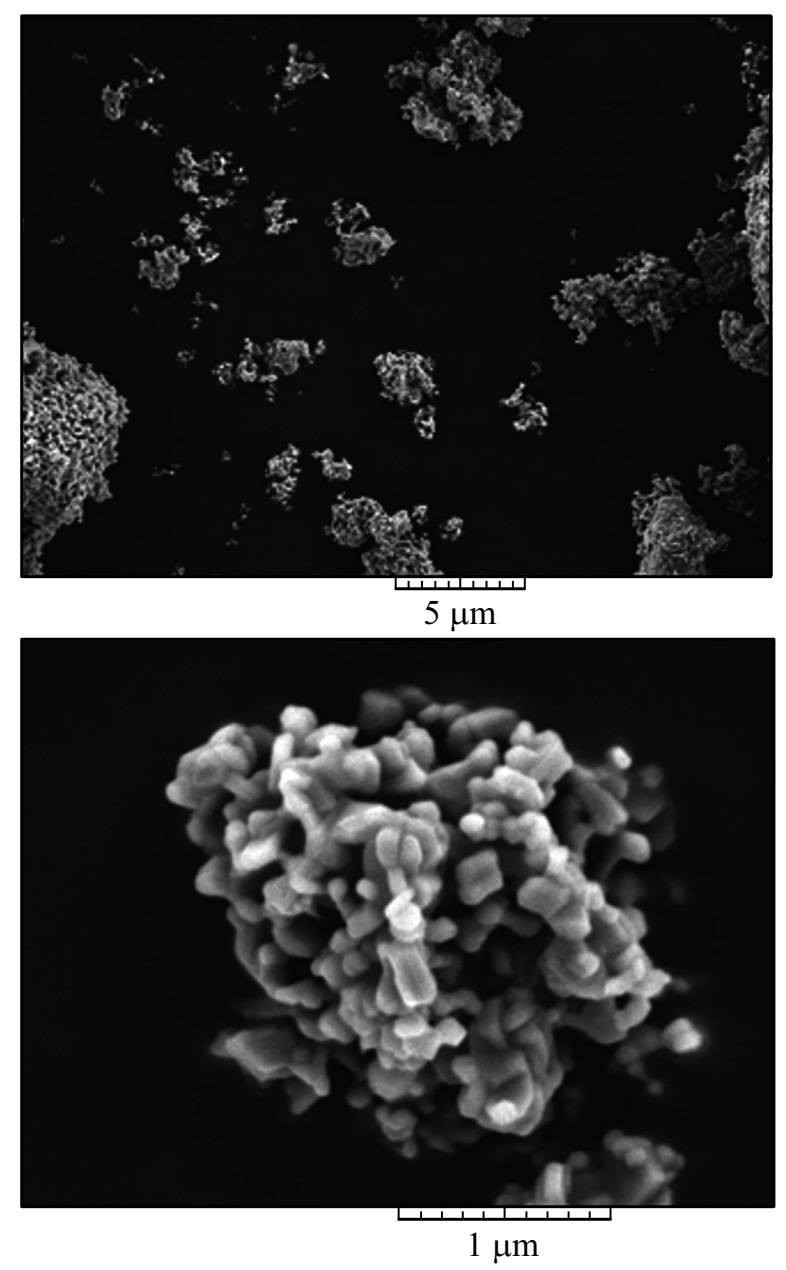

Рис. 3. Микрофотографии порошка гексаферрита стронция, полученного методом химического соосаждения, при различных увеличениях.

соосаждения, позволяют получить пластины с большими значениями степени магнитной текстуры.

Использование в технологии поликристаллических гексаферритов для получения ферритовых порошков метода химического соосаждения позволит создавать анизотропные гексаферриты с повышенной степенью магнитной текстуры при меньших энергозатратах.

Работа выполнена в рамках гранта Президента № МК1041.2017.8.

\section{Список литературы}

[1] Летюк Л.М., Костишин В.Г., Гончар А.В. Технология ферритовых материалов магнитоэлектроники. М.: МИСиС, 2005. 352 c

[2] Смит Я., Вейн Х. Ферриты. М.: Изд-во иностр. лит., 1962. $504 \mathrm{c}$.

[3] Костишин В.Г., Андреев В.Г., Налогин А.Г., Алексеев А.А., Читанов Д.Н., Белоконь Е.А. // ЖТФ. 2017. Т. 87. В. 6. C. 956-958. DOI: 10.21883/JTF.2017.06.44526.2074
[4] Mattei J.-L., Le C.N., Chevalier A., Maalouf A., Noutehou N., Queffelec P., Laur V. // J. Magn. Magn. Mater. 2018. V. 451. P. 208-213. DOI: 10.1016/j.jmmm.2017.10.121

[5] El Shater R.E., El-Ghazzawy E.H., El-Nimr M.K. // J. Alloys Compd. 2018. V. 739. P. 327-334. DOI: $10.1016 /$ j.jallcom.2017.12.228

[6] Barrera V., Betancourt I. // J. Phys. Chem. Solids. 2016. V. 93. P. 1-6. DOI: 10.1016/j.jpcs.2016.02.007

[7] Abraime B., Ait Tamerd M., Mahmoud A., Boschini F., Benyoussef A., Hamedoun M., Xiao Y., El Kenz A., Mounkachi O. // Ceram. Inter. 2017. V. 43. N 17. P. 15999 16006. DOI: 10.1016/j.ceramint.2017.08.187

[8] Kostishyn V.G., Timofeev A.V., Chitanov D.N. // J. Nano- and Electron. Phys. 2015. V. 7. N 4. P. 04066.

[9] Костишин В.Г., Тимофеев А.В., Читанов Д.Н. // Хим. технология. 2018. № 1. С. 11-15. 